Document downloaded from:

http://hdl.handle.net/10251/123501

This paper must be cited as:

Broatch, A.; Margot, X.; Garcia Tiscar, J.; Roig-Villanueva, F. (2018). Impact of simple surge-enhancing inlet geometries on the acoustic behaviour of a turbocompressor. International Journal of Engine Research. https://doi.org/10.1177/1468087418784125

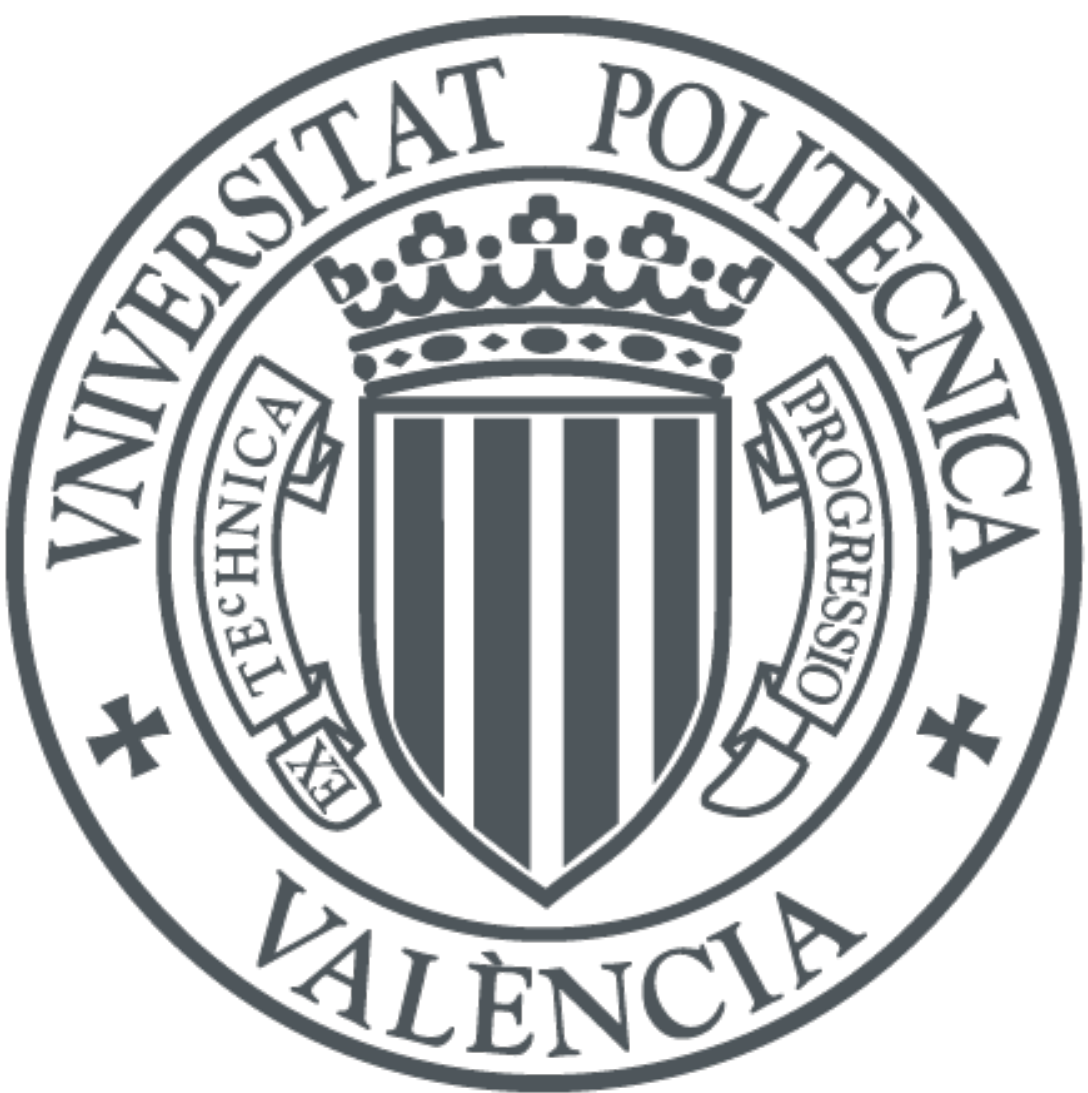

The final publication is available at

http://doi.org/10.1177/1468087418784125

Copyright SAGE Publications

Additional Information 


\title{
Impact of simple surge-enhancing inlet geometries on the acoustic behaviour of a turbocompressor
}

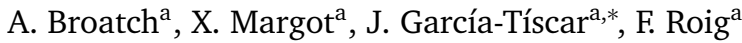 \\ ${ }^{a}$ CMT - Motores Térmicos, Universitat Politècnica de València, Camino de Vera, 46022 Valencia, Spain
}

\begin{abstract}
This paper reports the results of an experimental campaign where four different inlet geometries for the compressor of an automotive turbocharger were acoustically characterized. These four geometries (a straight pipe for reference, a tapered duct, a $90^{\circ}$ elbow and a reservoir) were selected for their potential for deep surge margin enhancement, while being simple enough to be commonly found in production vehicles. A detailed measurement of this surge margin enhancement was performed, together with acoustic measurements of both radiated and orifice noise at design conditions of best isentropic efficiency and also close to the deep surge limit. Results demonstrated that while all the proposed geometries indeed enlarged the usable air mass flow range, changes in the acoustic behaviour of the system could be positive, neutral, or even negative. It is therefore important to carefully consider accurate noise measurements before implementing these geometric solutions in production vehicles, and to further pursue research on the link between the characteristic flow pattern produced by each inlet geometry and the noise emission of the turbocompressor.
\end{abstract}

Keywords: Aeroacoustics, Turbocharging, Noise, Sound, Surge, NVH

\section{Introduction}

Turbochargers are ever more common in all kinds of internal combustion engines, even those of reduced size and spark ignition combustion [1] that used to be naturally-aspirated. However, along with the advantage of increased boosting pressure, turbochargers bring about specific issues such as lag, stalling operation, deep surge and worse noise, vibration and harshness (NVH) behaviour [2].

Moreover, many different inlet geometries are used to connect the air box of these engines to the turbocharger compressors. While the effect of inlet geometry in deep surge margin onset and its associated very low frequency fluctuations has been studied [3-6], the effect on the full spectrum acoustic emission at unstable operating conditions typical of the mild or marginal surge zone region, where flow is partially stalled, is not yet well documented.

As NVH issues of combustion-powered vehicles are becoming crucial for manufacturers due to customer and regulator requirements for quieter vehicles [7], especially taking into account the increased popularity of quieter electric vehicles, accounting for all sources of noise in the engine is a necessity.

Characterizing the turbocompressor as one of these sources is imperative, since not only it adds to the overall noise level of the car, but also introduces higher frequency content to the acoustic signature of the engine that is being perceived from the passenger cabin.
Since the shaft speed of the turbocharger group is much higher than that of the engine, high pitched sounds can be produced [8], upsetting the usual psychoacoustic 'masking' of higher frequency mechanical noise by the lower frequency combustion-generated noise [9] and thus creating in the customer the perception that a mechanical malfunction may be happening, or that the engine 'quality' is lower.

Unfortunately, scarce data is available in the literature regarding the acoustic effect of turbocompressor inlet geometries. However, Karim et al. [10] recently demonstrated that for instance inlet swirl vanes can achieve a reduction on the $4-12 \mathrm{kHz}$ noise band of the compressor, and Galindo et al. [11] reported an overall noise influence of different nozzles, although no frequency content analysis was performed.

However, many manufacturers have not yet implemented advanced devices flow control such as the aforementioned swirl vanes or swirl generators, convergent-divergent nozzles and so on. In most production cases, simpler geometries such as $90^{\circ}$ elbows or tapered ducts are used just in order to meet tighter packaging requirements or duct diameter matching.

In this paper, the acoustic behaviour of simple inlet geometries with surge enhancement capabilities commonly found in production vehicles is reported, with the aim of providing practical information to designers and manufacturers who may be considering the use of such geometries. Along with overall noise levels, spectral content is analyzed in order to highlight the effect of each geometry in the acoustic signature of the system at different working conditions.

*Corresponding author. Tel.: +34 963877 650, email: jorgarti@mot.upv.es 


\section{Experimental campaign}

The geometries selected for the experimental campaign were chosen from the most commonly seen in the literature regarding surge line optimization: a $90^{\circ}$ sharp elbow $[12,13]$, a tapered duct [14], and a reservoir [15]. In addition, a short straight pipe was also used as a reference. These four geometries can be seen in Fig. 1. While reservoirs are less common in production engines, they have been studied along the other two in the context of surge enhancement [16] and it is thus relevant to document its acoustic behaviour as well.

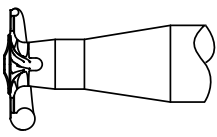

Tapered duct

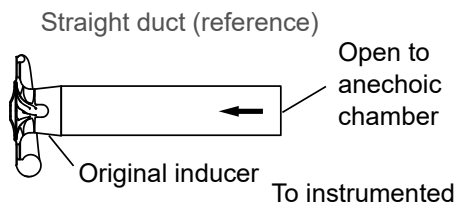

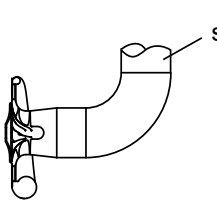

$90^{\circ}$ elbow

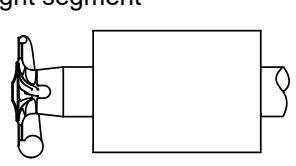

Reservoir
Figure 1: Drawing of the selected geometries. The straight pipe at the top was used standalone as a reference and also attached upstream of each geometry in order to measure the instantaneous pressure except for the tapered duct that used a wider pipe

\subsection{Anechoic turbocharger test rig setup}

These geometries were installed in a turbocharger test rig situated inside an anechoic chamber [17], which provided an adequate acoustic environment, free of the wall reflections that are common in standard turbocharger test rigs and engine cells. While in these cases it is necessary to resort to induct techniques to characterize the acoustic emission of the turbocharger [8], the anechoic environment allows external acquisitions. Thus, orifice noise measurements were carried out along with radiated noise recordings with the objective of characterizing the far-field acoustic emission as well. The later has the advantage of avoiding flow effects that may affect orifice measurements.

In order to simulate more realistic inlet conditions a short straight pipe was added upstream of each tested geometry. This short pipe included fast piezoelectric pressure transducers in order to accurately detect deep surge. However, no acoustic intensimetry could be performed as the pipes were too short for proper flow development $[18,19]$.

Fast pressure data was recorded by a Yokogawa digital oscilloscope, along with air mass flow on the outlet line and shaft speed information. The rest of the ancillary information about the turbocharger operation such as temperatures, pressures, etc., was recorded by an in-house DAQ system.

Measurements with each inlet geometric variant were carried out at a constant, representative shaft speed of $160 \mathrm{krpm}$. Operating conditions were brought close to the manufacturer's indicated surge limit for a standard straight duct, and then a precise deep surge characterization procedure was performed.

\subsection{Precise surge margin measurement}

Raw pressure data from one of the fast piezoelectric sensors was used to determine with high precision the air mass flow at which the compressor entered into deep surge conditions. In this way it can be ensured that the predicted influence of each geometry regarding the stability of the flow and thus the enlargement of the usable operating conditions is effectively attested.

When conditions were judged to be close enough to deep surge, the throttle valve was slowly closed to gradually decrease the mass flow, and all variables were continuously recorded, until the appearance of violent oscillations indicative of the onset of deep surge. Then, the throttle valve was completely opened to stabilize the turbocharger and prevent damage.

This pressure recording was then post-processed following a procedure similar to that described by Galindo et al. [16, 20]. Every $500 \mathrm{~ms}$ time-step a fast Fourier transform was applied to obtain the pressure spectra and then a frequency ratio $R_{f}$ between the acoustic power in the $0-50 \mathrm{~Hz}$ range and the acoustic power in the $50-100 \mathrm{~Hz}$ range was computed:

$$
R_{f}=\frac{\sum_{f=0}^{50}|\mathbf{P}(f)|^{2}}{\sum_{f=50}^{100}|\mathbf{P}(f)|^{2}}
$$

The onset of deep surge was considered when this power ratio reached values over 100. Data was then averaged between the two previous time steps in order to obtain the corresponding value of lowest allowable air mass flow. The non-dimensional pressure traces are represented in the upper plots of Fig. 2, along with the time-steps and power ratios. The bottom plot shows the lowest allowable mass flow obtained with this method for each geometry.

As seen in this figure, the straight duct is the first one to reach deep surge conditions. The tapered duct and the $90^{\circ}$ elbow pipe have similar higher margins until surge, while the reservoir delays this damaging condition even more, allowing approximately $10 \mathrm{~g} / \mathrm{s}$ of further air mass flow reduction.

\subsection{Acoustic results}

In addition to the effect on surge margin, the effect on external noise levels was evaluated. As stated previously, two different measurement systems were available in the anechoic chamber.

To capture the orifice noise, a free-field omni-directional microphone was situated at a distance of $10 \mathrm{~mm}$ from the inlet opening, as done in previous works for straight geometries $[21,22]$. In this case the microphone had to be repositioned each time the geometry was changed because of the different lengths and, in the case of the elbow, the orientation of the orifice had to be changed.

To measure externally radiated noise, the second system consisting in four equally-spaced free-field microphones 

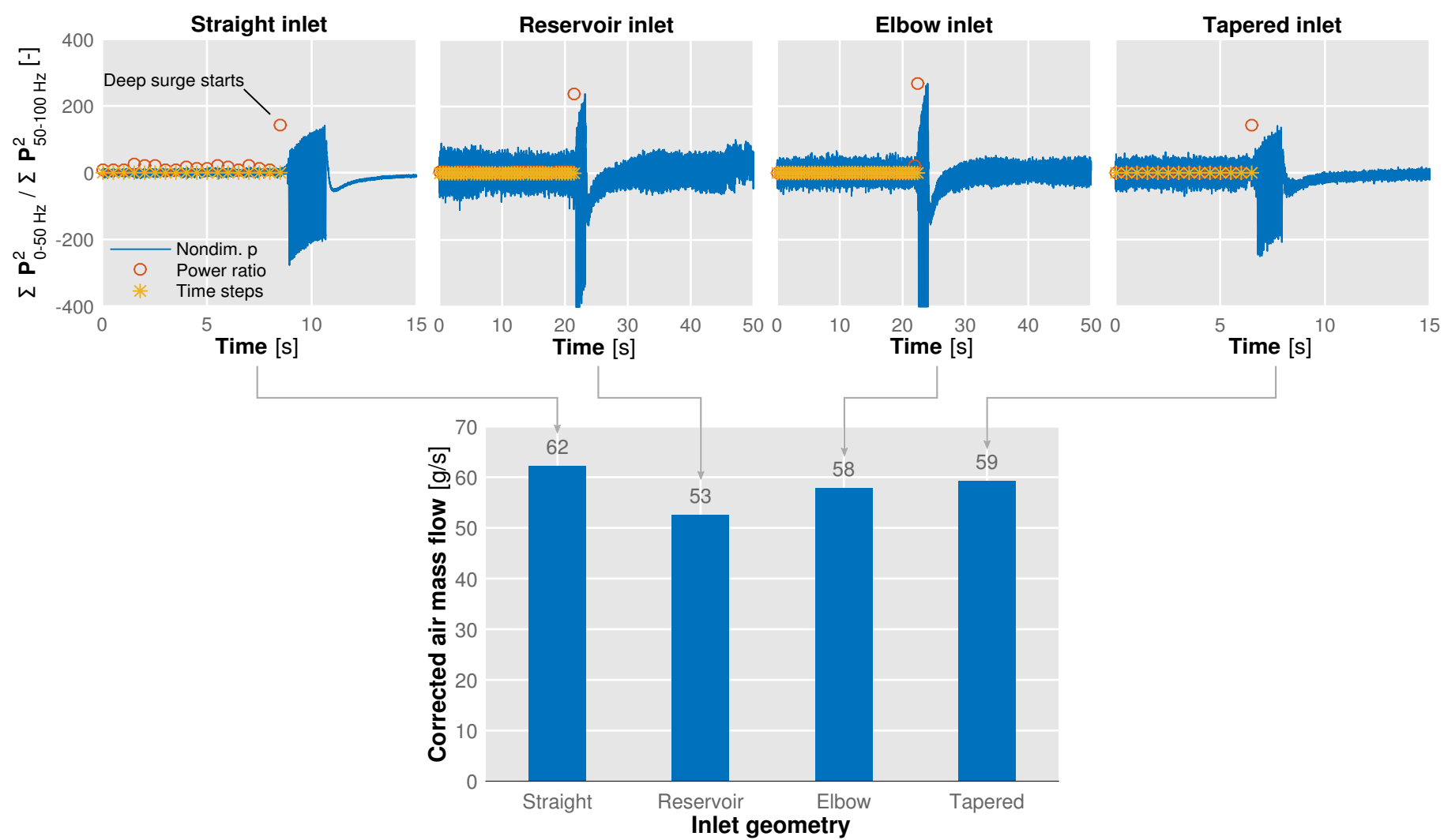

Figure 2: Non-dimensional pressure recording for each geometry when air mass flow was progressively reduced until reaching deep surge conditions. This gives a very accurate measurement of the minimum allowable air mass flow for each geometry, as shown in the bottom plot

placed at $1 \mathrm{~m}$ distance form the center of the inlet assembly was kept in the same place for all the tested geometries, replicating a method used for whole engines $[23,24]$. In both cases the microphones were calibrated prior to the measurements by using a Brüel \& Kjær pistonphone and data was captured using a PULSE ${ }^{\mathrm{TM}}$ DAQ system.

In order to obtain a broader characterization of the effect that the proposed geometries have on the acoustic output of the compressor, two different operating points were tested: one at design conditions (DC) of best isentropic efficiency and one at partially stalled conditions near deep surge (NS), marked in the compressor map shown in Fig. 3.

As each desired operating point was reached, repeated measurements were performed in close sequence until differences between consecutive measurements were negligible, thus signifying that the compressor had reached a steady state operation. Only then was the definitive data captured.

\subsubsection{Operating at design conditions}

The results of the overall sound pressure levels (SPL) for both orifice and radiated noise are shown in Fig. 4 for each selected geometry at the selected design condition. As seen, the reservoir presents the best acoustic behaviour overall, since it reduces the radiated noise of the system by $4 \mathrm{~dB}$ compared to the reference straight duct.

On the other hand, results for the noise radiated by the $90^{\circ}$ elbow and the tapered duct are very similar to the reference geometry, with SPL within $1 \mathrm{~dB}$ from the straight duct. It appears that in these two cases the geometry did not have any significant influence on the orifice noise.

It must be noted that in the case of the $90^{\circ}$ elbow inlet,

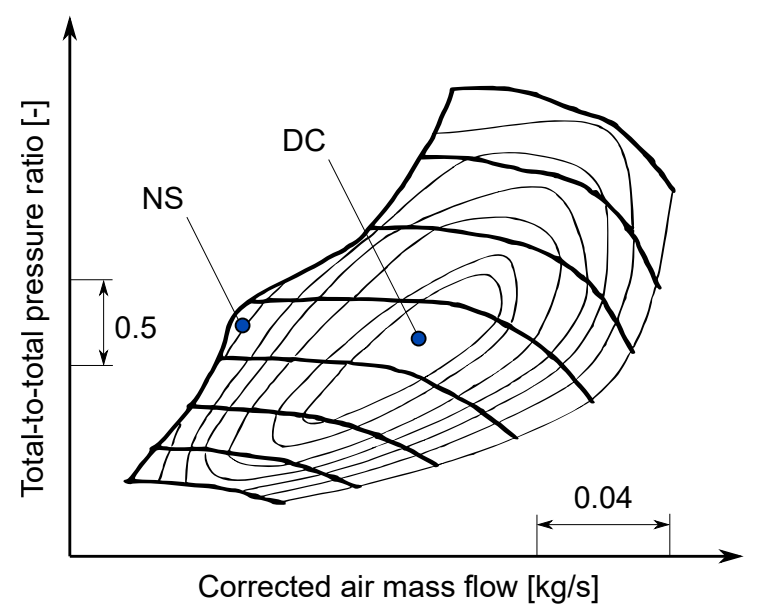

Figure 3: Compressor map for the selected turbocharger (straight duct), indicating characteristic speed lines, isentropic efficiency contours, and highlighting both the design condition (DC) and near surge (NS) operating points considered for the acoustic measurements 


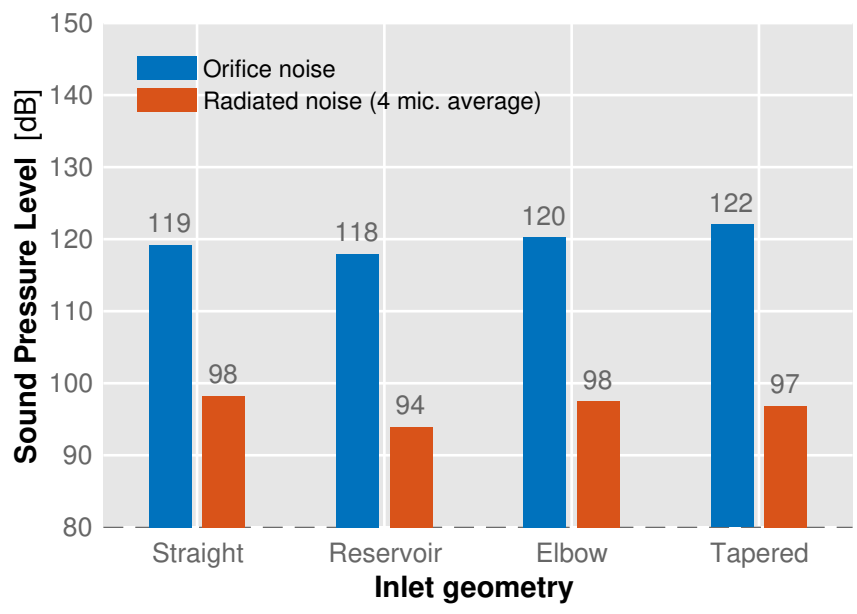

Figure 4: Comparison of orifice noise and averaged radiated noise measured in the anechoic chamber for each of the simple inlet geometries at design conditions (DC)

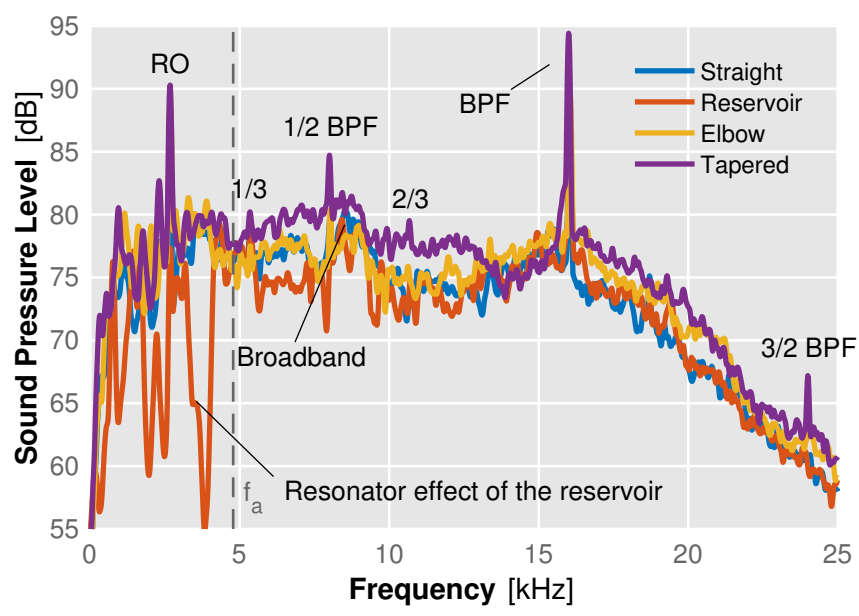

Figure 5: Comparison of orifice noise spectra for each of the inlet geometries at design conditions (DC). Dashed line shows the onset of the first higher order mode

radiated noise data is only taken from the top and bottom microphones, as the other two were situated in the plane of the elbow and thus the $1 \mathrm{~m}$ distance was not kept.

Regarding orifice noise, the reservoir and the elbow duct feature similar results to the reference straight duct. In the case of the tapered duct, however, the acoustic performance is degraded, as shown by the $3 \mathrm{~dB}$ increase in noise emission.

However, it is well known that overall noise is not the only parameter to characterize the acoustic response of a system. Especially for automotive engines and turbochargers the spectral signature of the emitted sound is important. On one hand, in order to attenuate the noise reaching the passengers' cabin, different techniques can be used for the insulation of the engine housing, more or less effective depending on the frequency content of the sound.

On the other hand, it is known that drivers like to judge the 'quality' of the vehicle on the basis of its perceived noise [25]. Especially in the case of sports vehicles the user expects deep,

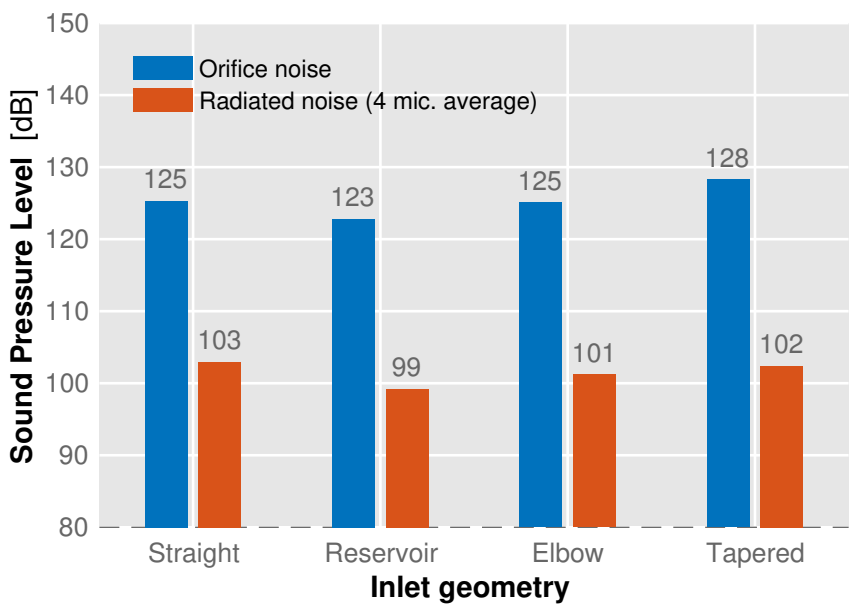

Figure 6: Comparison of orifice noise and averaged radiated noise measured in the anechoic chamber for each of the simple inlet geometries at the operating point near deep surge (NS)

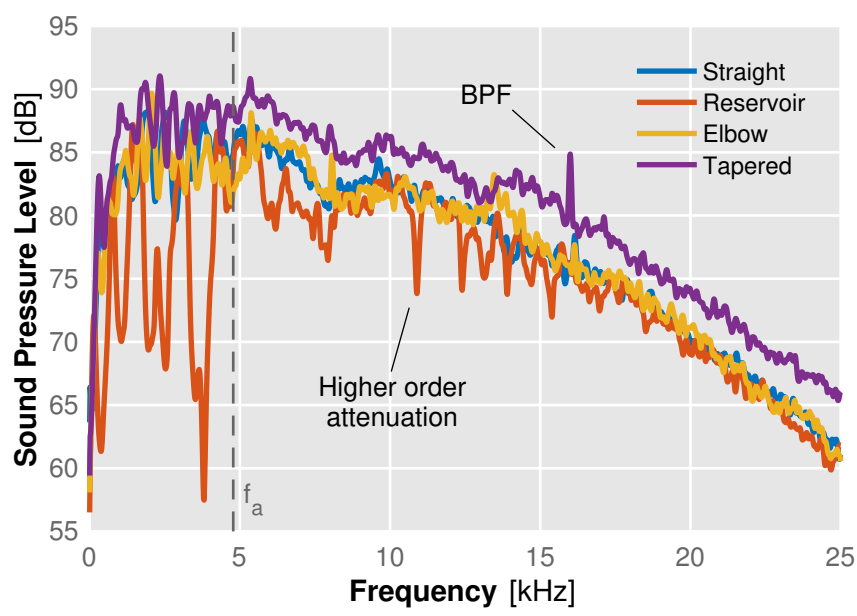

Figure 7: Comparison of orifice noise spectra for each of the inlet geometries at the operating point near deep surge (NS). Dashed line shows the onset of the first higher order mode

low frequency sounds, and may thus perceive the high-pitched, blowing sounds typical of the high shaft speed turbocharger as mechanical failures of the vehicle.

In Fig. 5 the different spectra recorded by the orifice microphone during each geometry test at design condition are plotted to analyze in detail the differences in the frequency response. It shows that the levels for the tapered duct are higher for the whole frequency range, while the inlets featuring the $90^{\circ}$ elbow and the reservoir remain closer to the reference straight pipe.

The most noticeable difference however, lies in the resonator effect of the reservoir that provides an important attenuation of noise levels at certain frequency bands. This acoustic attenuation is significantly higher in frequencies in the plane wave region of the spectrum, this is, frequencies lower than the cut-off frequency $f_{a}$ for which the first asymmetric acoustic mode begins to propagate.

According to Eriksson [26], this cut-off frequency can be 
calculated in circular ducts with mean flow by taking into account the local sound speed $a$, the mean Mach number $M$ and the duct diameter $D$ as indicated in Eq. 2. The required temperature was obtained by the measurements of two thermocouples, and the velocity was deducted from the air mass flow by continuity.

$$
f_{a}=1.84 \frac{a}{\pi D} \sqrt{1-M^{2}}=4.8 \mathrm{kHz}
$$

The strong peak visible at $16 \mathrm{kHz}$ corresponds to the well known phenomenon of Blade Passing Frequency (BPF) tonal noise [27], associated to the shaft speed $(\Omega)$ and the number of main blades $n_{\text {blades }}$ of the compressor:

$$
\mathrm{BPF}=\Omega \times n_{\text {blades }}=\frac{160 \mathrm{krpm}}{60 \mathrm{~s}} \times 6=16 \mathrm{kHz}
$$

This peak is accompanied by its $1 / 2$ and $3 / 2$ harmonics, which are also clearly seen in the figure. $1 / 3$ and $2 / 3$ harmonics also appear to be faintly present, although at much higher amplitude.

A broadband noise above the plane wave range can be seen peaking approximately at $8.5 \mathrm{kHz}$, although partially masked in the tapered case. This is similar to the tip clearance noise (TCN) described by Raitor and Neise [27], although it is not clear that this is the actual source mechanism [28, 29]. An attenuation of this TCN-like level is achieved by the reservoir, even if at this frequency higher order modes are already propagating.

Lastly, another clear peak can be observed well inside the plane wave range. This peak, also called rotation order (RO) in the literature [30], is similar in nature to those related to blade passing, although in this case it is not related to each individual blade, but rather to each revolution of the whole impeller:

$$
\mathrm{RO}=\Omega \times 1 \mathrm{rev}=\frac{160 \mathrm{krpm}}{60 \mathrm{~s}}=2.67 \mathrm{kHz}
$$

\subsubsection{Operating near deep surge}

For comparison with design conditions, Fig. 6 shows the result of both orifice and radiated noise measurements at an operating point near surge (NS). In order to provide comparable results, noise was measured at approximately the same air mass flow for all geometries, which was limited by the worse surge margin of the straight duct. It must be taken into account however that if the additional margin provided by the other geometries is used, noise behaviour level in that additional area of the map will be even worse as instabilities continue to grow in magnitude.

At this condition, there are again significant differences between the inlet geometries tested, which confirm the observations made for the design condition case. The radiated noise obtained from averaging the signals of the four microphones is lowest for the reservoir inlet, with a $4 \mathrm{~dB}$ reduction compared to the reference straight duct. The tapered duct seems to radiate at almost the same level as the straight pipe, with only $1 \mathrm{~dB}$ of difference. However, contrary to the design condition, the $90^{\circ}$ elbow also shows a $2 \mathrm{~dB}$ reduction with respect to the reference duct.

Regarding orifice noise, the reservoir featured a reduction in noise level of $2 \mathrm{~dB}$, slightly more important than in design conditions. The elbow instead featured the same level as the reference straight pipe. The tapered duct is confirmed as the one with the highest orifice noise level at $128 \mathrm{~dB}$, again $3 \mathrm{~dB}$ more than the reference straight geometry.

As for the spectral signature of the noise, plotted in Fig. 7 for the near surge condition, the main difference with respect to the design operating condition is the increase in lower and medium frequency content. The plane wave content in particular is boosted by approximately $10 \mathrm{~dB}$. This overall level rise of the lower frequencies masks previously detected phenomena such as the broadband noise elevation and BPF harmonics.

Indeed, the BPF peak itself is clearly diminished. According to [31], rotating, stalled low pressure bubbles and the recirculating backflow returning from the stalled zones of the diffuser to the inlet $[28,32]$ may interfere with the propagation of the BPF tonal noise from the blade tips and the diffuser area to the upstream inlet orifice. This kind of fluid-acoustic interaction, however, is difficult to investigate experimentally and calls instead for numerical simulations of the problem.

In any case, Fig. 7 shows that although the near surge conditions are quite different from the design conditions, the influence of the turbocharger inlet geometry on the spectral signature of the orifice noise is similar. This is an important result, as it supports the extrapolation of conclusions gathered from one operating point to others nearby.

Again the result for the elbow closely matches that of the reference straight duct, whereas the tapered duct shows higher levels at all frequencies. As in design conditions, the reservoir confirms its ability to attenuate certain narrowbands, especially in the plane wave range. In this case, however, these attenuation effects are also clearly present in regions of the spectrum where higher order acoustic modes are propagating, pointing again to some interaction between the complex fluid field at partially stalled conditions and the acoustic response of the system.

\section{Conclusions and future works}

This work has confirmed that the compressor inlet geometry has indeed an influence on the deep surge margin, even when very simple variations are used, ranging from $4.8 \%$ to $14.5 \%$ gain against straight ducts.

However, results also demonstrate that from the point of view of overall noise emission the inlet geometry has also influence, and not necessarily positive. The only significant reduction in radiated noise was achieved with the reservoir, up to $4 \mathrm{~dB}$ decrease. The $90^{\circ}$ elbow was practically neutral in terms of noise, but the tapered inlet increased orifice noise by $4 \mathrm{~dB}$. This is over the double of the acoustic energy output, and yet this is a quite popular geometric solution, due to its simplicity and ability to match different diameters in turbochargers and inlet piping. 
The influence of the inlet geometry on the frequency content of the acoustic output has also been demonstrated in this study. The reservoir attenuation effect is more prominent in the plane wave range and at selected narrow bands at higher frequencies, whereas the tapered duct appears to amplify the acoustic content at most frequencies.

Considering the tight packaging requirements for most turbocharger applications, the implementation of reservoirs to enhance the surge margin and attenuate $\mathrm{NVH}$ issues may prove to be difficult. On the other hand, data presented in this work attests to the potential of a $90^{\circ}$ elbow for improving surge behaviour while being acoustically neutral. This type of geometry may be further optimized by studying the influence of the orientation and radius of the elbow, as these parameters influence the flow field and thus the air presentation to the compressor downstream.

As a general conclusion, results of this work demonstrate that compressor inlet geometries intended to enhance surge margins can deteriorate NVH characteristics. In future works, further experimental and numerical investigations with different geometries at different operating conditions will be carried out in order to shed light on the link between the specific flow patterns induced by these geometries and the aeroacoustic signature of the turbocompressor.

\section{Acknowledgements}

The equipment used in this work has been partially supported by FEDER project funds "Dotación de infraestructuras científico técnicas para el Centro Integral de Mejora Energética y Medioambiental de Sistemas de Transporte (CiMeT)" [grant number FEDER-ICTS-2012-06], framed in the operational program of unique scientific and technical infrastructure of the Spanish Government.

\section{References}

[1] B. Hu, S. Akehurst, C. Brace, Novel approaches to improve the gas exchange process of downsized turbocharged spark-ignition engines: A review, International Journal of Engine Research 17 (6) (2016) 595618. doi : 10.1177/1468087415599866.

[2] H. Stoffels, M. Schroeer, NVH Aspects of a Downsized Turbocharged Gasoline Powertrain with Direct Injection, SAE Technical Paper 200301-1664. doi : 10.4271/2003-01- 1664.

[3] J. R. Serrano, X. Margot, A. Tiseira, L. M. García-Cuevas, Optimization of the inlet air line of an automotive turbocharger, International Journal of Engine Research 14 (1) (2013) 92-104. doi:10.1177/ 1468087412449085.

[4] L. Wang, C. Yang, B. Zhao, D. Lao, C. Ma, D. Li, The change of the inlet geometry of a centrifugal compressor stage and its influence on the compressor performance, Journal of Thermal Science 22 (3) (2013) 197-208. doi : 10.1007/s11630-013-0613-2.

[5] H. Tamaki, M. Unno, R. Tanaka, S. Yamaguchi, Y. Ishizu, Enhancement of centrifugal compressor operating range by control of inlet recirculation with inlet fins, Journal of Turbomachinery 138 (10) (2016) 101010. doi: 10.1115/1.4033187.

[6] E. Guillou, M. Gancedo, E. Gutmark, Experimental investigation of flow instability in a turbocharger ported shroud compressor, Journal of Turbomachinery 138 (6) (2016) 061002. doi : 10.1115/1.4032360.
[7] H. Stoffels, N. Collings, Effect of gasoline homogeneous charge compression ignition on engine acoustics and vibration, International Journal of Engine Research 8 (1) (2007) 51-62. doi:10.1243/ 14680874JER02706.

[8] A. Torregrosa, A. Broatch, R. Navarro, J. García-Tíscar, Acoustic characterization of automotive turbocompressors, International Journal of Engine Research 16 (1) (2015) 31-37. doi:10.1177/ 1468087414562866.

[9] J. A. Massey, J. A. Drallmeier, Identification of the dominant combustion characteristics on homogeneous charge compression ignition engine noise, International Journal of Engine Research 16 (4) (2015) 518-530. doi: $10.1177 / 1468087414535598$.

[10] A. Karim, K. Miazgowicz, B. Lizotte, A. Zouani, Computational aeroacoustics simulation of compressor whoosh noise in automotive turbochargers, SAE Technical Paper (2013-01-1880). doi:10.4271/ 2013- $01-1880$.

[11] J. Galindo, A. Tiseira, R. Navarro, D. Tarí, C. Meano, Effect of the inlet geometry on performance, surge margin and noise emission of an automotive turbocharger compressor, Applied Thermal Engineering 110 (2017) 875-882. doi:10.1016/j .applthermaleng . 2016.08.099.

[12] D. Li, C. Yang, M. Zhou, Z. Zhu, H. Wang, Numerical and experimental research on different inlet configurations of high speed centrifugal compressor, Science China Technological Sciences 55 (1) (2012) 174 181. doi : 10.1007/s11431-011-4635 - 2.

[13] A. Engeda, Y. Kim, R. Aungier, G. Direnzi, The inlet flow structure of a centrifugal compressor stage and its influence on the compressor performance, Journal of fluids engineering 125 (5) (2003) 779-785. doi: 10.1115/1.1601255.

[14] J. Galindo, F. Arnau, A. Tiseira, R. Lang, H. Lahjaily, T. Gimenes, Measurement and modeling of compressor surge on engine test bench for different intake line configurations, SAE Technical Paper (2011-010370). doi : 10.4271/2011-01-0370.

[15] R. Lang, Contribución a la Mejora del Margen de Bombeo en Compresores Centrífugos de Sobrealimentación, Ph.D. thesis, Universitat Politècnica de València (2011). doi: 10.4995/Thesis/10251/12331.

[16] J. Galindo, A. Tiseira, F. J. Arnau, R. Lang, On-engine measurement of turbocharger surge limit, Experimental Techniques 37 (1) (2013) 47-54. doi:10.1111/j.1747-1567.2010.00697.x.

[17] A. Broatch, J. Galindo, R. Navarro, J. García-Tíscar, Methodology for experimental validation of a CFD model for predicting noise generation in centrifugal compressors, International Journal of Heat and Fluid Flow 50 (2014) 134-144. doi : 10.1016/j . ijheatfluidflow. 2014. 06.006 .

[18] A. J. Torregrosa, A. Broatch, X. Margot, J. García-Tíscar, Experimental methodology for turbocompressor in-duct noise evaluation based on beamforming wave decomposition, Journal of Sound and Vibration 376 (2016) 60-71. doi: 10.1016/j.jsv.2016.04.035.

[19] Piñero, G. and Vergara, L. and Desantes, J. M. and Broatch, A., Estimation of velocity fluctuation in internal combustion engine exhaust systems through beamforming techniques, Measurement Science \& Technology 11 (11) (2000) 1585-1595. doi:10.1088/0957-0233/ $11 / 11 / 307$.

[20] J. Galindo, J. R. Serrano, C. Guardiola, C. Cervelló, Surge limit definition in a specific test bench for the characterization of automotive turbochargers, Experimental Thermal and Fluid Science 30 (5) (2006) 449-462. doi:10.1016/j. expthermflusci.2005.06.002.

[21] Y. Lee, D. Lee, Y. So, D. Chung, Control of Airflow Noise From Diesel Engine Turbocharger, SAE Technical Paper (2011-01-0933). doi: 10 . 4271/2011- 01 - 0933 .

[22] N. Figurella, R. Dehner, A. Selamet, K. Tallio, K. Miazgowicz, R. Wade, Noise at the mid to high flow range of a turbocharger compressor, Noise Control Engineering Journal 62 (5) (2014) 306-312. doi: 10.3397/ $1 / 376229$.

[23] D. Evans, A. Ward, Minimizing Turbocharger Whoosh Noise for Diesel Powertrains, SAE Technical Paper 2005-01-2485. doi:10.4271/ 2005- $01-2485$.

[24] C. Teng, S. Homco, Investigation of Compressor Whoosh Noise in Automotive Turbochargers, SAE Int. J. of Passeng. Cars-Mech. Syst. 2 (1) (2009) 1345-1351. doi : 10.4271/2009-01-2053.

[25] M. Nor, M. Fouladi, H. Nahvi, A. Ariffin, Index for vehicle acoustical comfort inside a passenger car, Applied Acoustics 69 (4) (2008) 343- 
353. doi:10.1016/j. apacoust.2006.11.001.

[26] L. J. Eriksson, Higher order mode effects in circular ducts and expansion chambers, Journal of the Acoustical Society of America 68 (1980) 545. doi: 10.1121/1.384768.

[27] T. Raitor, W. Neise, Sound generation in centrifugal compressors, Journal of Sound and Vibration 314 (2008) 738 - 756. doi:10.1016/j jsv.2008.01.034.

[28] A. Torregrosa, A. Broatch, X. Margot, J. García-Tíscar, Y. Narvekar, R. Cheung, Local flow measurements in a turbocharger compressor inlet, Experimental Thermal and Fluid Science 88 (2017) 542-553. doi: 10.1016/j .expthermflusci. 2017.07.007.

[29] J. Galindo, A. Tiseira, R. Navarro, M. López, Influence of tip clearance on flow behavior and noise generation of centrifugal compressors in near-surge conditions, International Journal of Heat and Fluid Flow 52 (2015) 129-139. doi:10.1016/j.ijheatfluidflow.2014.12.004.
[30] F. Mendonça, O. Baris, G. Capon, Simulation of Radial Compressor Aeroacoustics using CFD, in: Proceedings of ASME Turbo Expo 2012, no. GT2012-70028, ASME, 2012, pp. 1823-1832. doi:10.1115/ GT2012-70028.

[31] A. Broatch, J. Galindo, R. Navarro, J. García-Tíscar, A. Daglish, R. Sharma, Simulations and measurements of automotive turbocharger compressor whoosh noise, Engineering Applications of Computational Fluid Mechanics 9 (1) (2015) 12-20. doi : 10. 1080/19942060. 2015. 1004788.

[32] F. Hellstrom, E. Gutmark, L. Fuchs, Large eddy simulation of the unsteady flow in a radial compressor operating near surge, Journal of Turbomachinery 134 (5) (2012) 051006. doi : 10.1115/1.4003816. 